\title{
Bleeding Gastric Lipoma Resected by Endoscopic Submucosal Dissection
}

\author{
Adil S. Mir ${ }^{1}$, Varun Kesar ${ }^{2}$, Mohamed Sageer ${ }^{3,4}$, Douglas Grider $^{5,6}$, Vikas Chitnavis ${ }^{7}$ \\ 1. Internal Medicine, Carilion Clinic, Roanoke, USA 2. Gastroenterology, Virginia Tech Carilion School of Medicine, \\ Roanoke, USA 3. Gastroenterology and Hepatology, Veterans Affairs Medical Center, Salem, USA 4. \\ Medicine/Gastroenterology, Virginia Tech, Roanoke, USA 5. Basic Science Education, Virginia Tech Carilion School of \\ Medicine, Roanoke, USA 6. Pathology, Carilion Roanoke Memorial Hospital, Roanoke, USA 7. Gastroenterology, \\ Carilion Clinic, Roanoke, USA
}

Corresponding author: Adil S. Mir, dr.adilshamim@gmail.com

\begin{abstract}
Gastric lipomas are slow-growing benign lesions of the stomach that are often detected incidentally. Most cases are asymptomatic but larger lesions may become symptomatic, thereby requiring treatment. Multiple endoscopic modalities have been used for resection in the past. We present the case of a 67-year-old patient who presented with upper GI bleeding secondary to a gastric lipoma, which was successfully resected by endoscopic submucosal dissection.
\end{abstract}

Categories: Gastroenterology

Keywords: gastric lipoma, bleeding lipoma, endoscopic submucosal dissection

\section{Introduction}

Gastric lipomas (GLs) are benign tumors composed of well-differentiated adipose tissue. GLs are rare and account for nearly $5 \%$ of the GI tract lipomas, about $3 \%$ of the benign tumors of the stomach, and less than $1 \%$ of all gastric tumors [1-3]. Within the stomach, lipomas are more commonly found in the antral region [2]. Most GLs are asymptomatic and found incidentally during endoscopic procedures or imaging for various other indications. However, GLs may become symptomatic by virtue of their size (usually more than $4 \mathrm{~cm}$ ) and/or location [2]. Presenting symptoms may include abdominal discomfort or pain, dyspepsia, early satiety, nausea, vomiting, gastric outlet obstruction, or GI bleeding. Ulceration with bleeding is the most common manifestation of GLs and is seen in nearly 50\% of the cases [2]. Whereas symptomatic subserosal lipomas have traditionally been managed by open procedures like enucleation, exploratory laparotomy, and gastrotomy, submucosal lipomas are usually amenable to endoscopic resection. We present a case of a large GL complicated by GI bleeding which was successfully removed by endoscopic submucosal dissection (ESD).

Received 06/18/2020 Review began 06/23/2020 Review ended 06/24/2020 Published 06/29/2020

๑) Copyright 2020

Mir et al. This is an open access article distributed under the terms of the Creative Commons Attribution License CC-BY 4.0., which permits unrestricted use, distribution, and reproduction in any medium, provided the original author and source are credited.

\section{Case Presentation}

A 67-year-old male with a history of hereditary hemochromatosis presented for the evaluation of anemia. Workup included an esophagogastroduodenoscopy (EGD), which showed a large gastric antral submucosal mass (nearly $5 \mathrm{~cm}$ size) below the incisura angularis (Figure 1) with a positive 'cushion' or 'pillow' sign (Figure 2). No signs of bleeding were noted at this time. 


\section{Cureus}

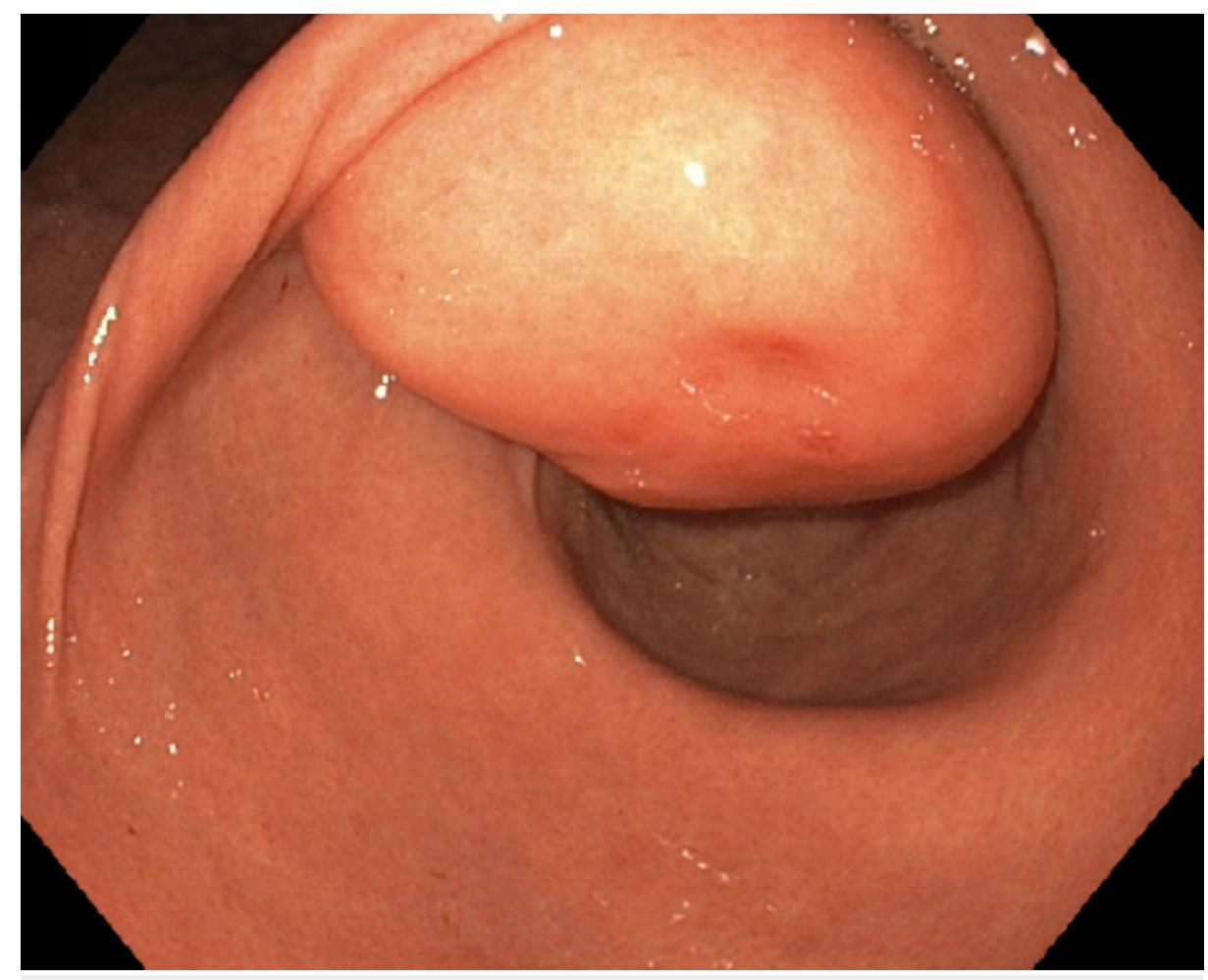

FIGURE 1: Gastric antral mass with a smooth surface below the incisura angularis

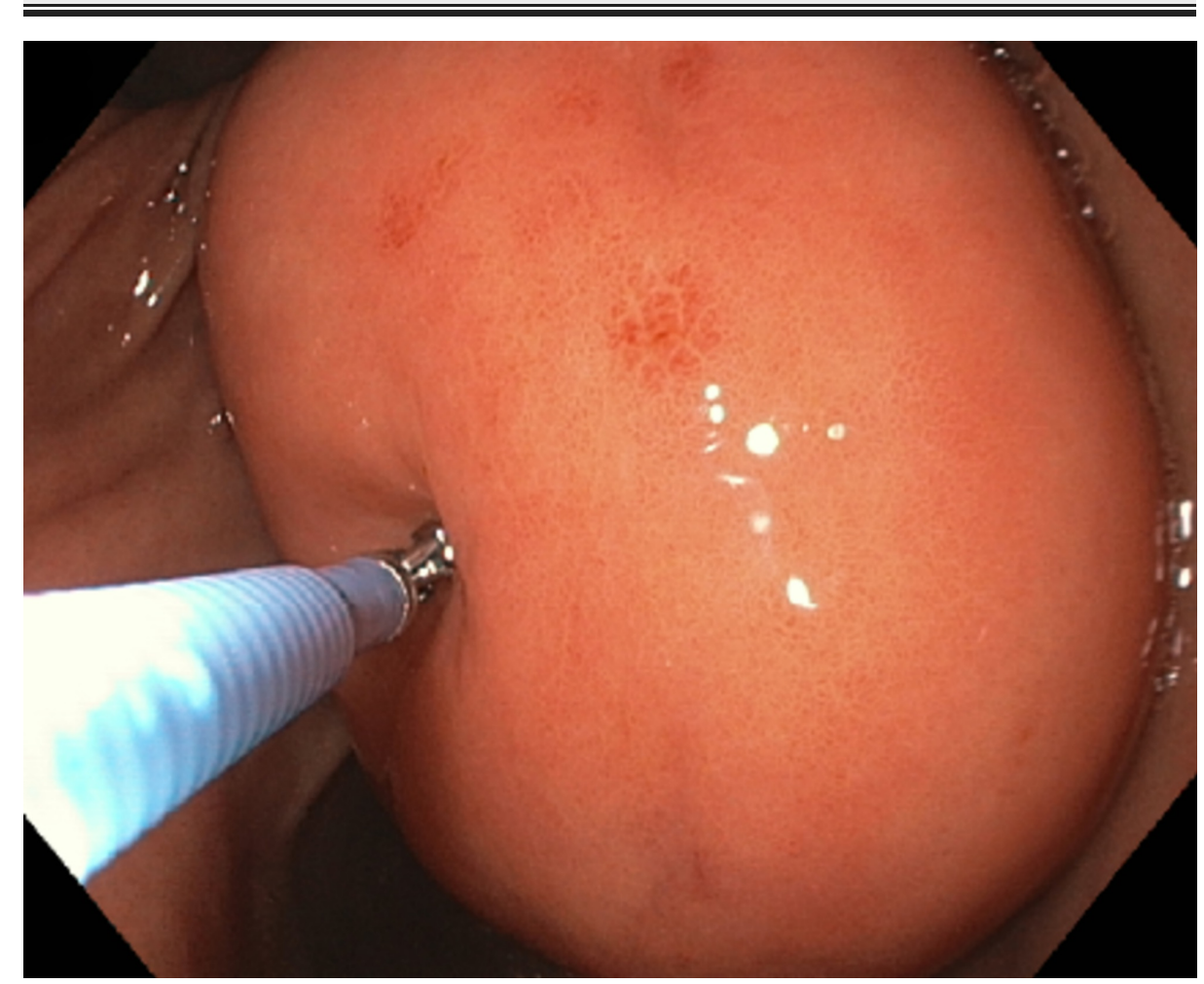

FIGURE 2: Pillow sign or cushion sign (application of mild pressure using a biopsy forceps causes indentation of the soft mass)

CT scan showed a well-circumscribed mass within the lumen of the gastric antrum measuring $4.1 \times 3.3 \mathrm{~cm}$, likely representing a GL (Figures 3,4), and the patient was discharged with outpatient follow-up. 


\section{Cureus}

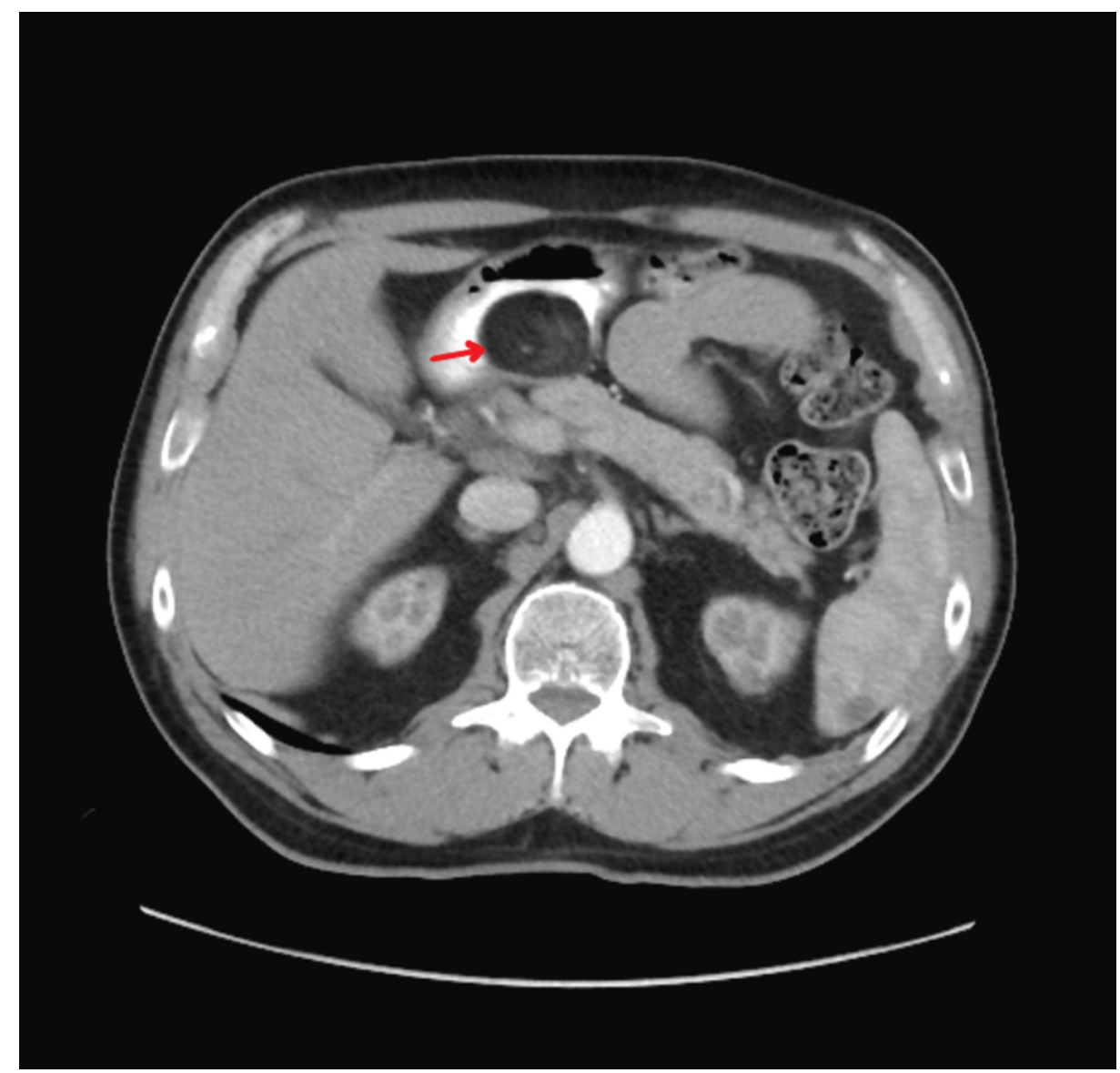

FIGURE 3: CT image showing a well-circumscribed mass in the lumen of the gastric antrum (arrow - axial view)

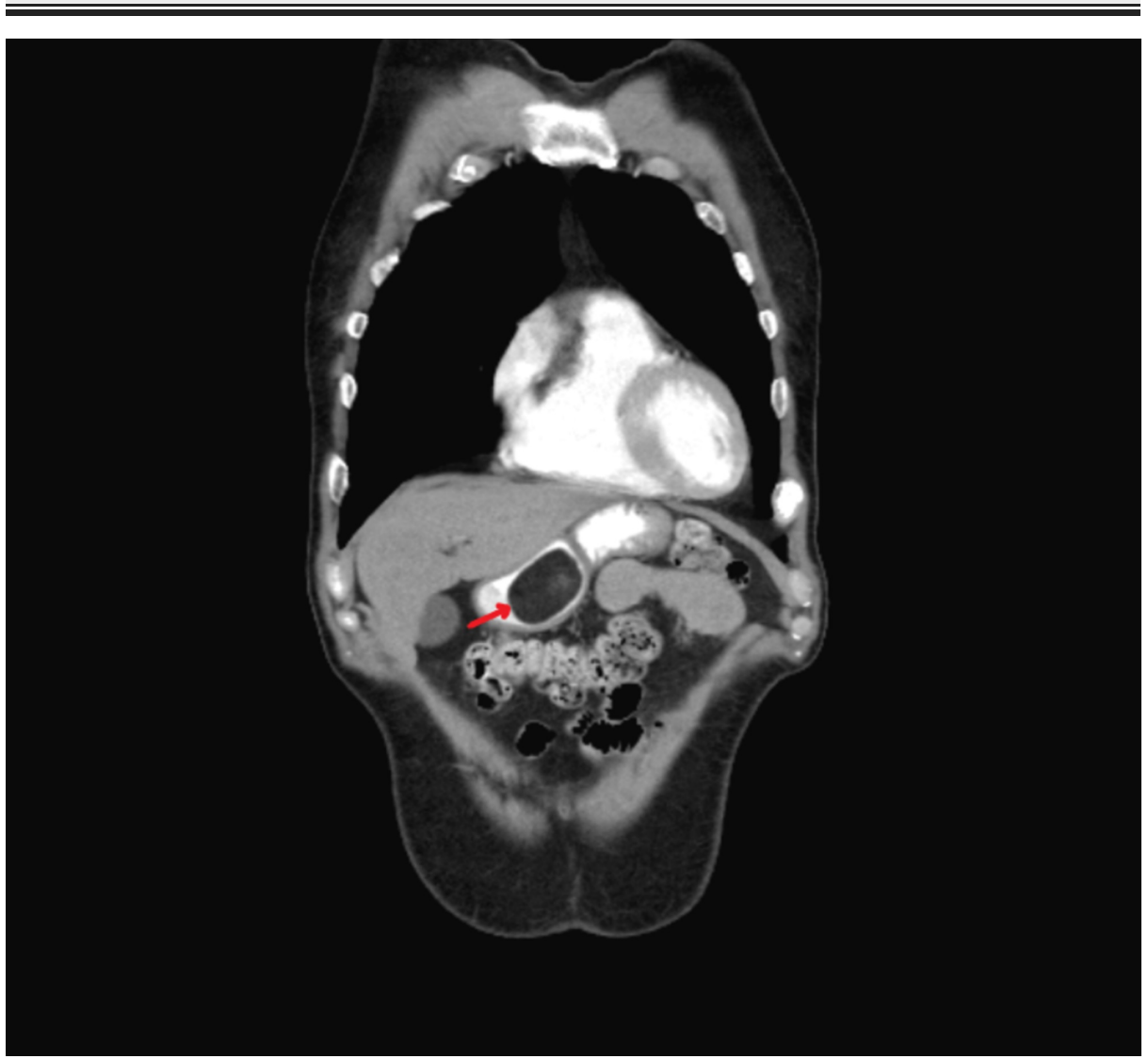




\section{Cureus}

FIGURE 4: CT image showing homogeneous gastric mass with a welldefined border (arrow - coronal view)

Two years later, the patient presented with melena and coffee-ground emesis. Repeat EGD showed the previously detected antral mass with a surface ulceration (Figure 5). Endoscopic ultrasound (EUS) showed hyperechoic subepithelial lesion arising from the submucosa consistent with a lipoma. Subsequently, this lesion was unroofed exposing fat and bite biopsies were obtained that showed focal erosive gastritis (negative for Helicobacter pylori) and benign well-differentiated adipocytes in the submucosa. These findings are consistent with a submucosal lipoma pushing the mucosa into the stomach lumen with resultant irritant gastritis.

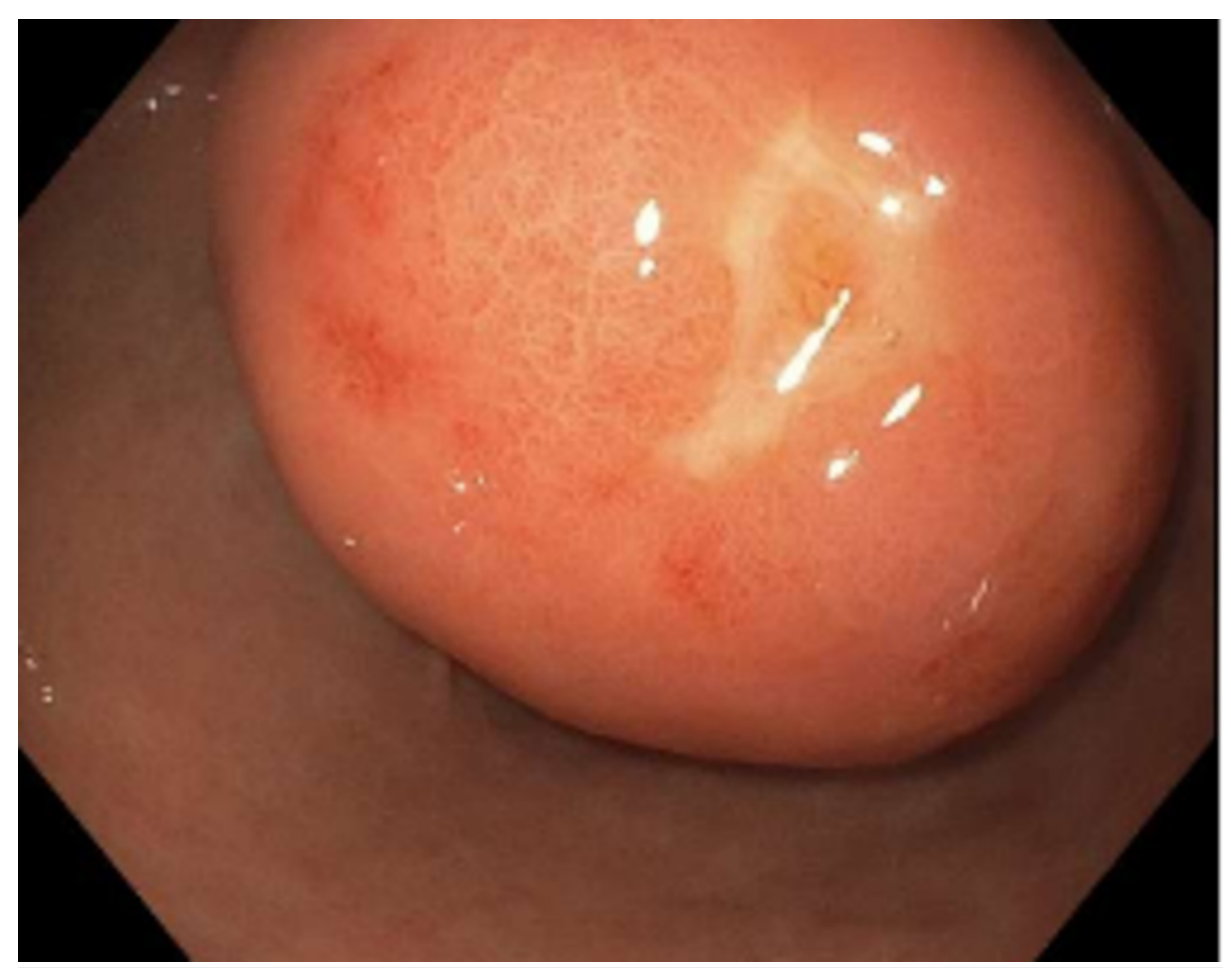

FIGURE 5: Gastric antral mass with a surface ulcer

Subsequently, the patient underwent a repeat EGD with ESD and extirpation of a yellow-colored 7-cm submucosal lipoma followed by careful cauterization of the bleeders (Figure 6). The ESD site was finally closed with a single running non-absorbable suture (Apollo OverStitch, Apollo Endosurgery Inc, Austin, TX) (Figure 7). Histopathology confirmed a submucosal lipoma (Figure 8). There were no procedure-related complications and the patient was discharged with recommendations to follow up as outpatient. 


\section{Cureus}

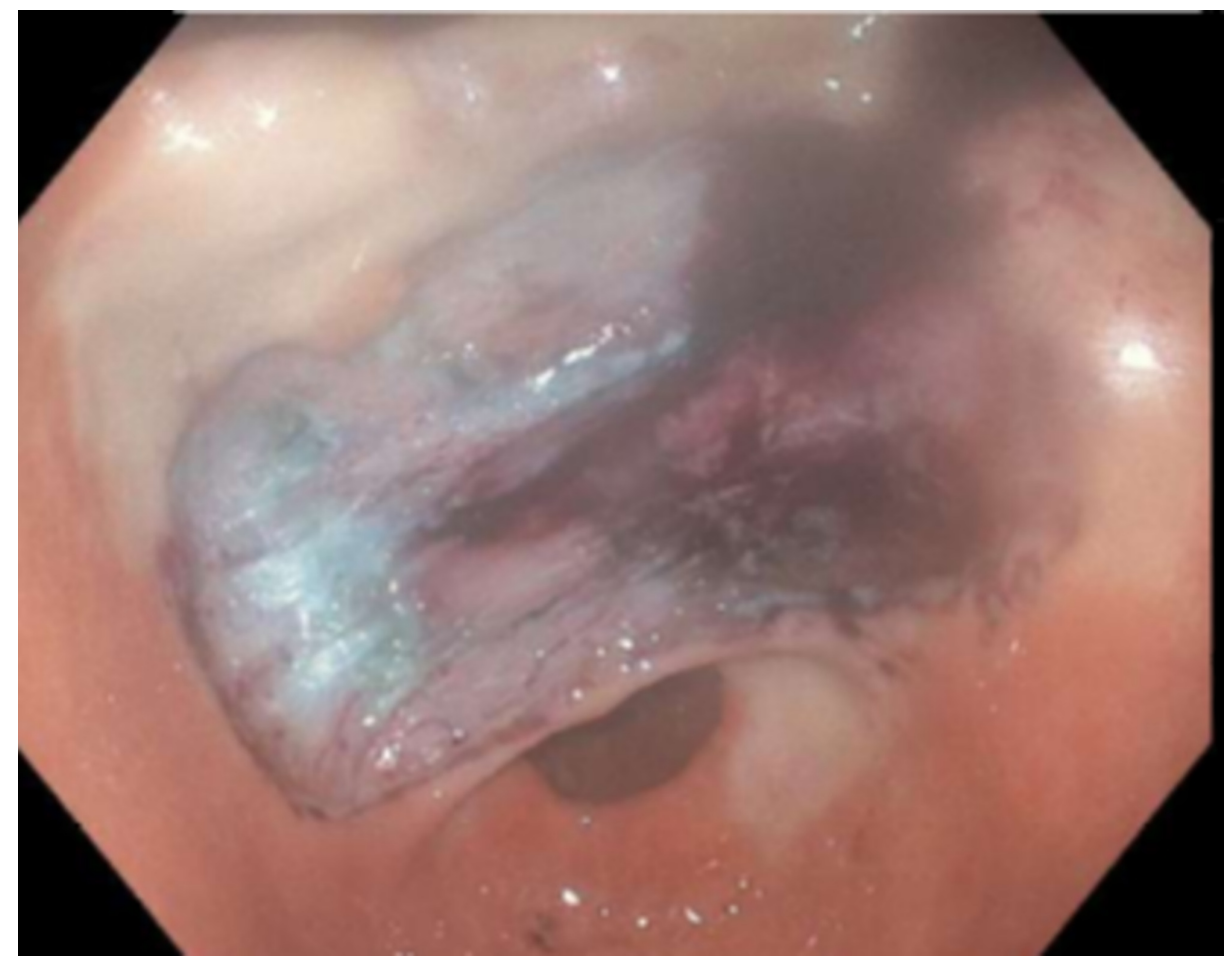

FIGURE 6: Endoscopic view of the gastric lipoma resection site after endoscopic submucosal dissection and cauterization

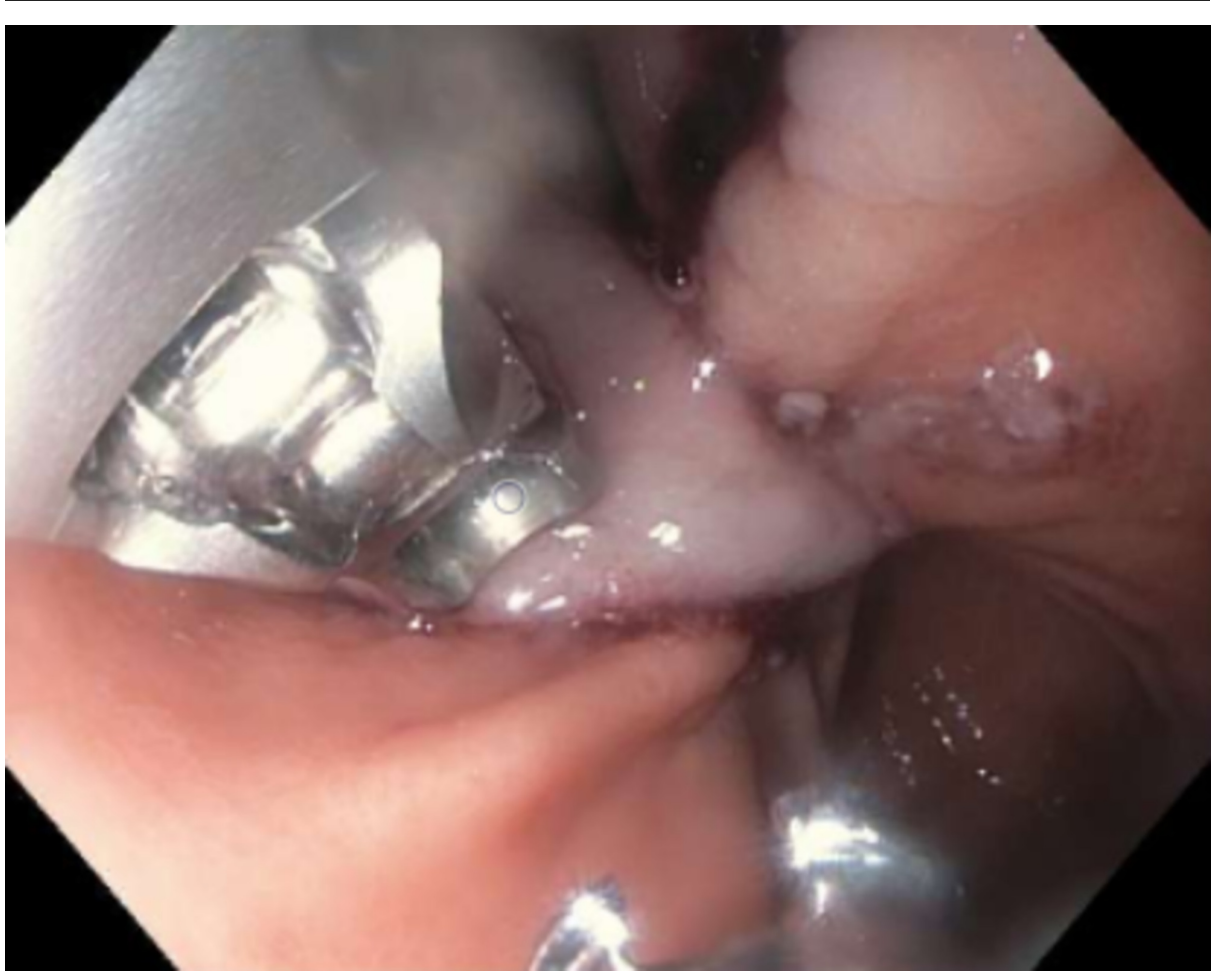

FIGURE 7: Endoscopic submucosal dissection site closed with single non-absorbable suture 


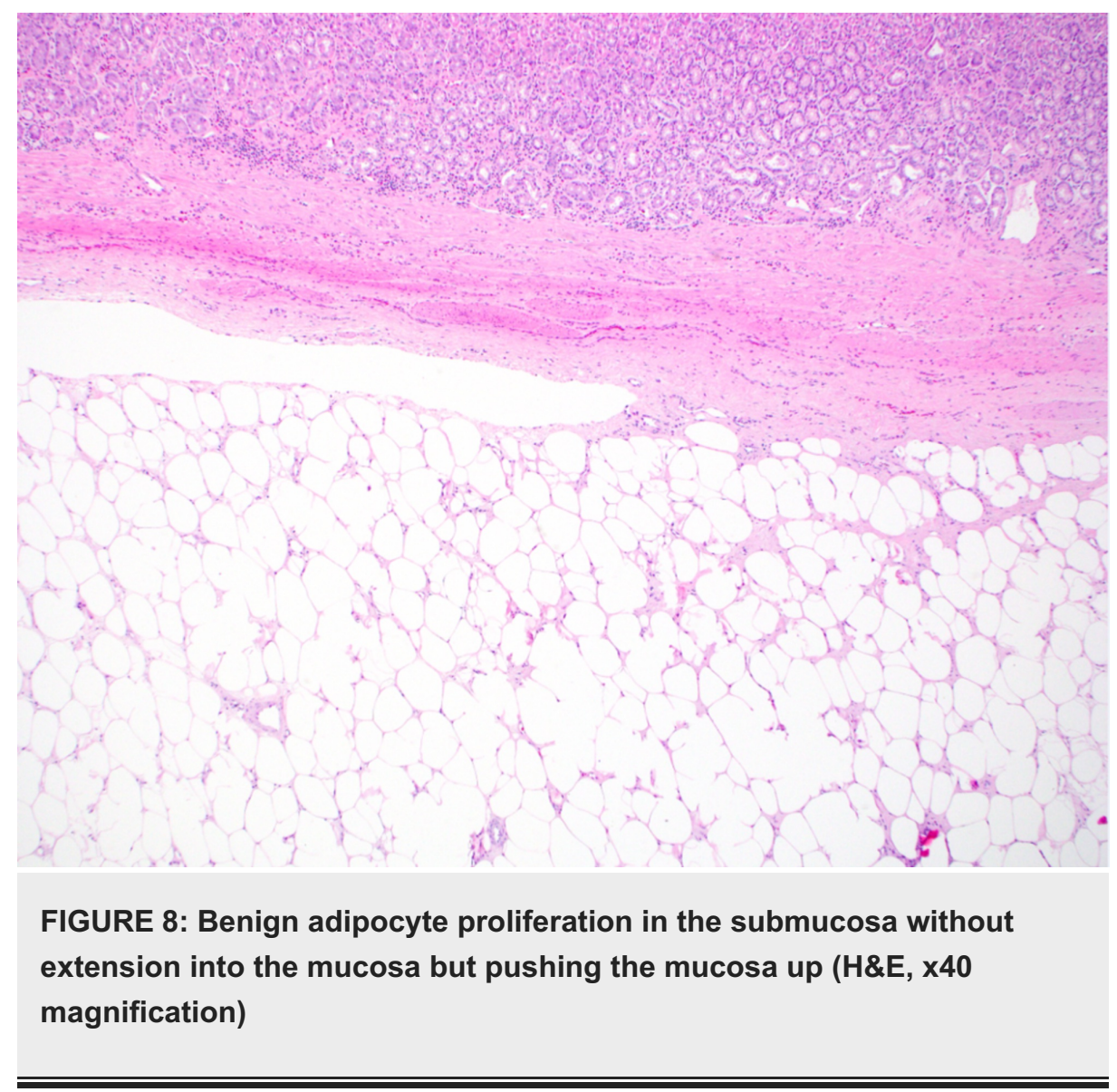

\section{Discussion}

GLs are slow-growing benign tumors, more common in women as compared to men, and the average age at diagnosis in most cases is around 50 to 70 years [4]. Grossly, lipomas are yellowish appearing soft lesions with a smooth surface. The 'cushion or pillow sign' (Figure 2) (application of mild pressure using a biopsy forceps causes indentation of the soft mass), the 'naked fat sign' (extrusion of yellow fat from the mucosal breakdown spot on the lipoma after biopsy), and the 'tenting sign' (mucosa overlying the lipoma can be lifted and moved using a biopsy forceps) may support the diagnosis on gross examination [2,5]. CT imaging not only helps in diagnosis but also helps differentiate lipomas from other extramucosal tumors (like lymphoma or gastrointestinal stromal tumors). Typically, on CT imaging, lipomas appear to have welldefined borders with a homogeneous hypodensity of -70 and -120 Hounsfield units (HU) (Figures 3, 4) [2]. On EUS, lipomas appear as well-localized hyperechoic masses whereas on fat-suppressed MRI lipomas appear as uniformly localized hypodensities [3,4]. Histologic specimen to confirm the diagnosis can be obtained using fine needle aspiration cytology (FNAC) or sometimes biopsy, which may not be needed in most cases as the imaging and EUS features are characteristic [2].

As mentioned above, GI bleeding secondary to large GLs is not uncommon. In such cases, erosions and ulcerations are often noted during endoscopy. Ulcerated GLs are usually $>4 \mathrm{~cm}$ in size, as in our case [6,7]. It has been debated that increased size of the lipoma may potentiate mucosal ischemia, leaving it vulnerable to the erosive effects of acid and mechanical effects of ingested food [4]. Although malignant transformation of GLs is rare, the possibility should always be borne in mind in case of large ulcerated masses that may present with obstructive features or bleeding. The diagnosis of liposarcoma can significantly alter the treatment decisions $[2,6]$.

Asymptomatic GLs less than $2 \mathrm{~cm}$ in size that are incidentally diagnosed may only require observation, whereas symptomatic lesions that are $>4 \mathrm{~cm}$ in size may need intervention [8]. GLs $<2 \mathrm{~cm}$ may be successfully treated with aspiration lumpectomy or strip biopsy [9]. Traditionally, large and symptomatic lesions were treated by surgery. However, with the advent of less invasive advanced endoscopic techniques, endoscopic resection is preferred option for submucosal GLs [10]. Endoscopic techniques used include snare resection, unroofing and enucleation, endoscopic mucosal resection (EMR), and ESD [10-12].

ESD of large GLs can be technically challenging, time consuming, and carries a significant risk of perforation. However, ESD has been used with success for the resection of subepithelial lesions including lipomas $[10,12,13]$. Also, due to a greater depth of resection, ESD is likely to be more effective in preventing recurrences as compared to other conventional techniques. Besides, ESD also allows for en bloc resection 


\section{Conclusions}

GLs are often incidentally diagnosed on endoscopy. EUS and imaging can help in diagnosis. Tissue diagnosis may be needed for confirmation or to rule out an underlying liposarcoma. The above case demonstrates that ESD can be used safely for the endoscopic resection of large submucosal GLs. The procedure requires more expertise and has a higher learning curve but is very effective in the definitive management of submucosal GLs.

\section{Additional Information}

\section{Disclosures}

Human subjects: Consent was obtained by all participants in this study. Conflicts of interest: In compliance with the ICMJE uniform disclosure form, all authors declare the following: Payment/services info: All authors have declared that no financial support was received from any organization for the submitted work. Financial relationships: All authors have declared that they have no financial relationships at present or within the previous three years with any organizations that might have an interest in the submitted work. Other relationships: All authors have declared that there are no other relationships or activities that could appear to have influenced the submitted work.

\section{References}

1. Krasniqi AS, Hoxha FT, Bicaj BX, Hashani SI, Hasimja SM, Kelmendi SM, Gashi-Luci LH: Symptomatic subserosal gastric lipoma successfully treated with enucleation. World J Gastroenterol. 2008, 14:5930-5932. 10.3748/wig. 14.5930

2. Krishnaraj B, Dhanapal B, Shankar G, Sistla SC, Galidevara I, Suresh A: Gastric lipoma: a rare cause of haematemesis. Ann R Coll Surg Engl. 2018, 100:41-43. 10.1308/rcsann.2017.0209

3. Cappell MS, Stevens CE, Amin M: Systematic review of giant gastric lipomas reported since 1980 and report of two new cases in a review of 117110 esophagogastroduodenoscopies. World J Gastroenterol. 2017, 23:5619-5633. 10.3748/wjg.v23.i30.5619

4. Ichinose M, Hikichi T, Kanno Y, et al.: A case of gastric lipoma resected by endoscopic submucosa dissection with difficulty in preoperative diagnosis. Fukushima J Med Sci. 2017, 63:160-164. 10.5387/fms.2016-19

5. Taylor AJ, Stewart ET, Dodds WJ: Gastrointestinal lipomas: a radiologic and pathologic review . AJR Am J Roentgenol. 1990, 155:1205-1210. 10.2214/ajr.155.6.2122666

6. Thompson WM, Kende AI, Levy AD: Imaging characteristics of gastric lipomas in 16 adult and pediatric patients. AJR Am J Roentgenol. 2003, 181:981-985. 10.2214/ajr.181.4.1810981

7. Ramdass MJ, Mathur S, Seetahal-Maraj P, Barrow S: Gastric lipoma presenting with massive upper gastrointestinal bleeding. Case Rep Emerg Med. 2013, 2013:506101. 10.1155/2013/506101

8. Termos S, Reslan O, Alqabandi O, et al.: Giant gastric lipoma presenting as GI bleed: enucleation or resection?. Int I Surg Case Rep. 2017, 41:39-42. 10.1016/i.ijscr.2017.10.004

9. Kajiyama T, Hajiro K, Sakai M, et al.: Endoscopic resection of gastrointestinal submucosal lesions: a comparison between strip biopsy and aspiration lumpectomy. Gastrointest Endosc. 1996, 44:404-410. 10.1016/s0016-5107(96)70089-5

10. Suarez AL, Dufault DL, Mcvey MC, Shetty A, Elmunzer BJ: Stepwise endoscopic resection of a large gastric lipoma causing gastric outlet obstruction and GI bleeding. Gastrointest Endosc. 2016, 84:180. 10.1016/j.gie.2016.02.036

11. Shim CS, Jung IS: Endoscopic removal of submucosal tumors: preprocedure diagnosis, technical options, and results. Endoscopy. 2005, 37:646-654. 10.1055/s-2005-861477

12. Lee KJ, Kim GH, Park DY, et al.: Endoscopic resection of gastrointestinal lipomas: a single-center experience. Surg Endosc. 2014, 28:185-192. 10.1007/s00464-013-3151-9

13. Kobara $\mathrm{H}$, Mori $\mathrm{H}$, Rafiq K, et al.: Indications of endoscopic submucosal dissection for symptomatic benign gastrointestinal subepithelial or carcinoid tumors originating in the submucosa. Mol Clin Oncol. 2013, 1:1002-1008. 10.3892/mco.2013.177 